\title{
Barium Defaecating Proctography: Experience from a Tertiary Referral Center
}

\author{
Cindy Sze Wan Chew ${ }^{1,2}$ Elaine Ee-Min Yeap ${ }^{3}$ Patrick J. O'Dwyer ${ }^{4}$ \\ ${ }^{1}$ Department of Radiology, University Hospital Hairmyres, \\ Hairmyres, United Kingdom \\ ${ }^{2}$ School of Medicine, Dentistry and Nursing, University of Glasgow, \\ Glasgow, United Kingdom \\ ${ }^{3}$ Department of Surgery, Queen Elizabeth University Hospital \\ Glasgow, Glasgow, United Kingdom \\ ${ }^{4}$ Department of Gastrointestinal Surgery, University of Glasgow, \\ Glasgow, United Kingdom \\ Address for correspondence Cindy Sze Wan Chew, MB, ChB, \\ MRCS, FRCR, MSc, Department of Radiology, University Hospital \\ Hairmyres, Eaglesham Road, Hairmyres G75 8RG, United Kingdom \\ (e-mail: chewszewan@aol.com).
}

J Gastrointestinal Abdominal Radiol ISGAR 2021;4:28-32.

\begin{abstract}
Keywords

- barium defaecating proctogram

- pelvic floor dysfunction

- long term follow-up

Objective Pelvic floor dysfunction (PFD) is a major health care problem predominately affecting the elderly female. It impairs quality of life and patients increasingly expect a solution. Barium defaecating proctography (BDP) is frequently used in the assessment of patients with PFD. The aim of this study was to present our findings from BDP and to look at the proportion of patients who went on to have surgery following their investigations. Methods All patients who underwent BDP in a tertiary referral center were identified retrospectively from the computerized radiology information system. Demographic data and radiologic findings were extracted. Data regarding those who had surgery were retrieved from the anonymized patient registry.

Results A total of 671 patients had a BDP during the study period. The main symptoms investigated were obstructed defecation or chronic constipation (64\%). Complete barium evacuation was observed in $70 \%$ of the patients, while $17 \%$ were noted to have incomplete and $13 \%$ no evacuation. A large rectocele $(>5 \mathrm{~cm})$ was noted in $38 \%$ while nearly $5 \%$ had frank prolapse. There was no significant association between a rectocele and any of the presenting symptoms. Seventy-eight (12\%) patients went on to have operation, of which $17(22 \%)$ had multiple procedures. Three patients ended up with a permanent stoma.

Conclusion BDP contributes to decision making in patients with PFD. However, results need to be interpreted with caution and in conjunction with other tests and clinical examination to maintain a low rate of operation and reduce the risk of adverse outcomes for these patients.
\end{abstract}

\section{Introduction}

Pelvic floor dysfunction (PFD) is a major health care problem predominantly affecting aging females. ${ }^{1}$ Unlike many other conditions, it is a global problem with implications for health care professionals across the world. ${ }^{2}$

PFD is a general term, used to describe a wide range of functional clinical problems characterized by symptoms of

published online

November 23, 2020
DOI https://doi.org/

$10.1055 / \mathrm{s}-0040-1719241$

ISSN 2581-9933. defecatory dysfunction, pelvic organ prolapse, chronic pelvic pain, dyspareunia, urinary and fecal incontinence. ${ }^{3}$ These can also be anatomically grouped to anterior pelvic compartment symptoms, predominantly urinary and sexual organ dysfunction, or posterior pelvic compartment symptoms, comprising of colorectal dysfunction. However, multicompartment symptomatology is widely recognized, and

(C2020. Indian Society of Gastrointestinal and Abdominal Radiology. This is an open access article published by Thieme under the terms of the Creative Commons Attribution-NonDerivative-NonCommercial-License, permitting copying and reproduction so long as the original work is given appropriate credit. Contents may not be used for commercial purposes, or adapted, remixed, transformed or built upon. (https://creativecommons.org/licenses/by-nc-nd/4.0/).

Thieme Medical and Scientific Publishers Pvt. Ltd. A-12, 2nd Floor, Sector 2, Noida-201301 UP, India 
physical examination can be challenging or inaccurate. ${ }^{4}$ The development of PFD is multifactorial. Major predisposing causative factors include childbirth, pelvic surgery, age, obesity, constipation, and genetic factors. ${ }^{5}$

Symptoms of PFD can cause major impediments on the quality of life and is a recognized important aspect in women's health care needs. To date, there are a variety of surgical and nonsurgical treatments available with the aim of restoring pelvic floor anatomy. Imaging such as barium defaecating proctogram (BDP) is an important adjunct for the assessment of pelvic floor abnormalities to aid the diagnosis and identify patients who will benefit from surgical treatment of PFD.

The aim of this study was to present our findings from BDP and to look at the proportion of patients who went on to have surgery following their investigations.

\section{Methods}

All patients who underwent BDP between 2009 and 2014 in a single tertiary referral center were identified retrospectively from the computed radiological information system. The examinations were all performed by a radiologist with an interest in PFD. Demographic data and radiological findings were extracted. Data regarding treatment plan and surgery were retrieved from an anonymized centralized patient registry. ${ }^{6}$

BDP was performed as described by Yang et al. ${ }^{7}$ The procedure is performed with the patient sitting on a specially commissioned and built clear Perspex commode between the C-arms of an Artis zee (Siemens Healthineers, Munich, Germany). At the beginning of the examination, barium/ potato paste (150-mL Baritop 100 [Sanochemia Diagnostics, $\mathrm{UK}$, warm water, and desiccated mash potato powder) is injected into the rectum in the left lateral decubitus position and the patient is then moved onto the commode. The patient is asked to defecate and the full examination is recorded with video fluoroscopy. The small bowel, vagina, and urinary bladder are not routinely opacified. Small bowel is opacified with barium (Baritop) in patients suspected of having an enterocoele from the history or during the examination. Measurements were taken in the active phase. Rectocele size was measured as the distance between the interpolated anterior anorectal axis and the anterior-most portion of the rectocele-classified as present if greater than $2 \mathrm{~cm}$ and large if measurement exceeds $5 \mathrm{~cm}$. Cystocele was diagnosed if the descent of the anterior vagina such that the urethra-vesical junction or any anterior point proximal to this was less than $3 \mathrm{~cm}$ above the plane of the hymen. Enterocoele (or sigmoidocele) was present if bowel is seen herniating into the Pouch of Douglas, between the rectum and vagina. For the purpose of this study, rectal prolapse was graded into rectal intussusception, rectoanal intussusception, or external rectal prolapse (-Fig. 1).

\section{Results}

A total of 671 patients who had BDP between 2009 and 2014 were identified. The majority $(94 \%)$ of patients were female with a median age of 51 years (range 16-88). Most of the referrals (74\%) were from Gynecology (-Table 1). The main symptoms investigated were obstructed/incomplete defecation and chronic constipation ( $n=431,64 \%)$. Others included prolapse (11\%), soiling/incontinence, or mixed symptoms (11\%) and rectocele (3\%). Eighty-three patients (12.4\%) had previous surgery for PFD.

Normal defecation was seen in only $74(11 \%)$ patients. One-third of the patients investigated had low-lying perineum, while almost half (48\%) had prominent pelvic floor descent. However, complete barium evacuation was observed in the vast majority of 467 (70\%) patients, 116 (17\%) were noted to have incomplete evacuation, and 81 (13\%) patients had no evacuation (-Table 2 ).

Rectocele was present in 380 patients (56.6\%) of which $67 \%$ were large or moderate $(>5 \mathrm{~cm})$. Enterocoele was demonstrated in $79(11.8 \%)$ patients and frank prolapse in 32. Lesser degree of mucosa laxity was present in 82 patients. There was no significant association between any of the presenting symptoms and the presence of a rectocele ( - Table 3 ).

After a median follow-up of 4 years (range 2-7), $78(12 \%)$ patients underwent subsequent surgery. A total of 101 procedures were performed. The majority of the procedures $(n=58)$ were colorectal, followed by gynecological $(n=34)$ but only nine urological procedures were performed. - Table 4 shows a breakdown of the procedures of all three specialties. Anal procedures included injection of bulking agents and excision of prolapsed mucosa. The
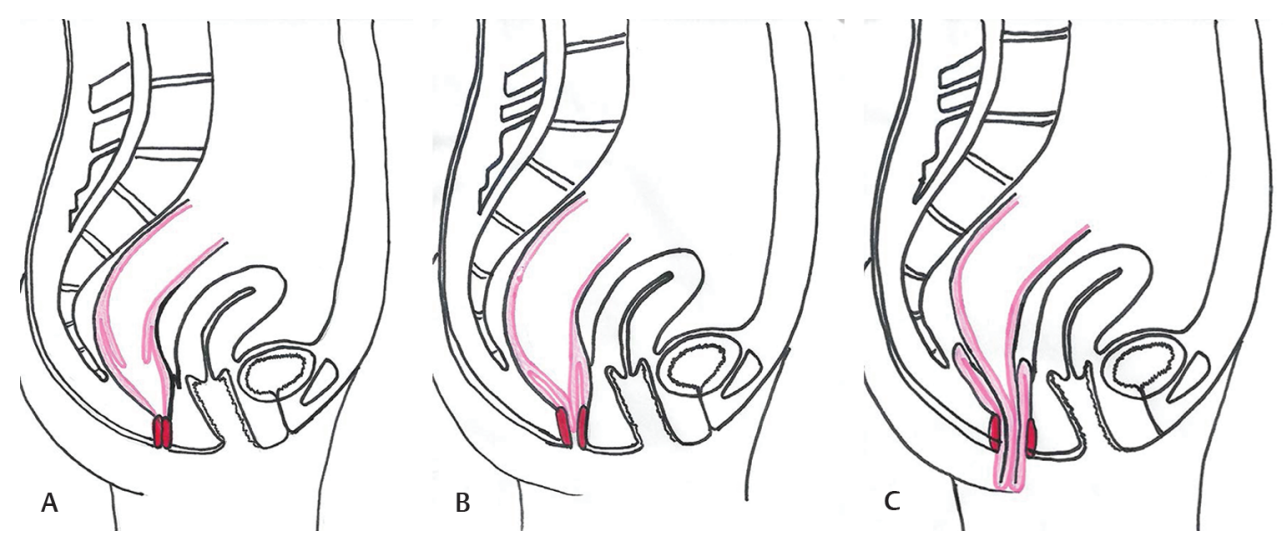

Fig. 1 Rectal intussusception (A), recto-anal intussusception (B), and rectal prolapse (C). 
Table 1 Demographics and source of referral

\begin{tabular}{|l|l|}
\hline & $N$ \\
\hline $\begin{array}{l}\text { Total number of patients underwent barium } \\
\text { proctography }\end{array}$ & 671 \\
\hline F: M & $629: 42$ \\
\hline Median age (range) years & $51(16-88)$ \\
\hline Surgical referral & $173(26 \%)$ \\
\hline Gynecology referral & $498(74 \%)$ \\
\hline $\begin{array}{l}\text { Previous surgery for rectocele/prolapsed/pelvic } \\
\text { floor repair }\end{array}$ & $83(12 \%)$ \\
\hline
\end{tabular}

Table 2 Barium proctographic findings

\begin{tabular}{|l|l|}
\hline Barium proctographic findings & $N(\%)$ \\
\hline Normal & $74(11)$ \\
\hline Low perineal lie & $201(30)$ \\
\hline Prominent pelvic floor descent & $325(48)$ \\
\hline Evacuation & \\
\hline Complete & $467(70)$ \\
\hline Incomplete & $116(17)$ \\
\hline No evacuation & $81(13)$ \\
\hline Rectocele present & $380(57)$ \\
\hline Small rectocele $(>2 \mathrm{~cm} ;<5 \mathrm{~cm})$ & 126 \\
\hline Moderate/large $(>5 \mathrm{~cm})$ & 254 \\
\hline Enterocoele present & $79(11)$ \\
\hline Prolapse/Intussusception & \\
\hline Lax rectal mucosa entering anal canal & $56(8.3)$ \\
\hline Lax rectal mucosa exiting anal canal & $56(3.9)$ \\
\hline Frank prolapse & $32(4.7)$ \\
\hline
\end{tabular}

Table 3 Association between symptoms and the presence of a rectocele

\begin{tabular}{|l|l|l|}
\hline Symptoms & Patient number & $\begin{array}{l}\text { No. with } \\
\text { rectocele (\%) }\end{array}$ \\
\hline Chronic constipation & 108 & $32(29.6 \%)$ \\
\hline Obstructed defecation & 241 & $103(42.7 \%)$ \\
\hline Incomplete evacuation & 82 & $31(37.8 \%)$ \\
\hline Other & 240 & $88(36.6 \%)$ \\
\hline Total & 671 & $254(37.8 \%)$ \\
\hline
\end{tabular}

Note: $p=$ NS for all groups when compared with total (chi-square test).

majority of minor urologic procedures included dilation of urethral strictures or cystoscopy with injection of botulinum toxin into the bladder wall.

Seventeen (15\%) patients underwent multiple operations. Of those, three (18\%) ended up with permanent stoma. Most operations were undertaken by a single specialty, eight involved two specialties and one involved all three specialties (-Fig. 2). -Figures 3-5 illustrate examples of rectocele, enterocele and rectal prolapse on BDP.
Table 4 Breakdown of operations performed across specialties

\begin{tabular}{|l|l|l|}
\hline $\begin{array}{l}\text { Colorectal } \\
\text { operations } \\
N=58\end{array}$ & $\begin{array}{l}\text { Gynecology } \\
\text { operations } \\
\mathbf{N}=\mathbf{3 4}\end{array}$ & $\begin{array}{l}\text { Urology } \\
\text { operations } \\
\mathbf{N}=\mathbf{9}\end{array}$ \\
\hline $\begin{array}{l}\text { Prolapse } \\
\text { surgery (26) }\end{array}$ & $\begin{array}{l}\text { Colporrhaphy (19) } \\
\text { Transvaginal }\end{array}$ & lleal conduit (2) \\
Other (7) \\
surgeryoid (18) & tape (7) & \\
Colectomy (3) & Hysterectomy (3) & \\
Loop stoma (3) & Prolapse & \\
Anal surgery (8) (2) & Other (3) & \\
\hline
\end{tabular}

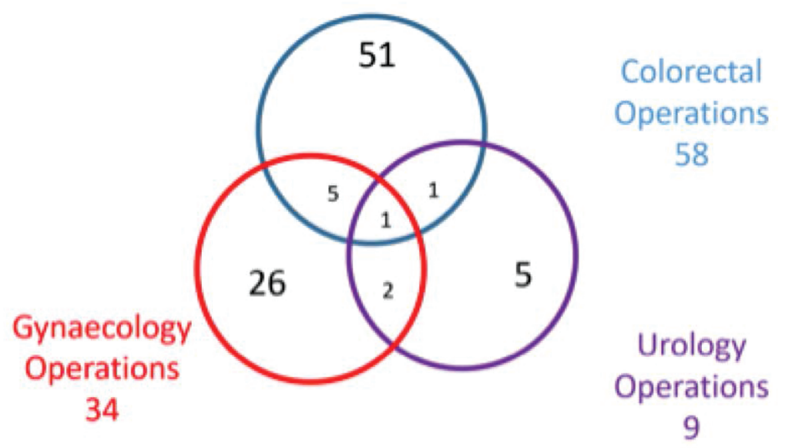

Fig. 2 Operations performed by specialty.

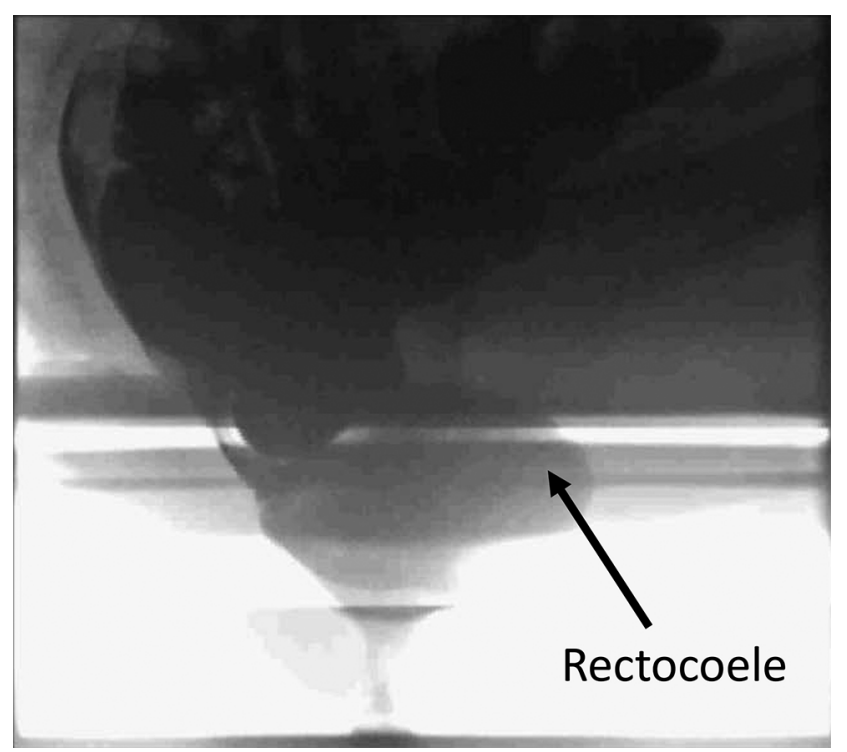

Fig. 3 Barium defaecating proctogram demonstrating a large rectocele (arrow).

\section{Discussion}

Despite growing interest in anorectal and PFD as a cause of bowel-related symptoms, the pathophysiology and anatomy involved are still poorly understood. Our audit is from a large cohort of patients in Scotland who have long-term follow-up following BDP. There was a low incidence of normal examinations (11\%) while $38 \%$ were noted to have a rectocele. These findings are similar to that previously 


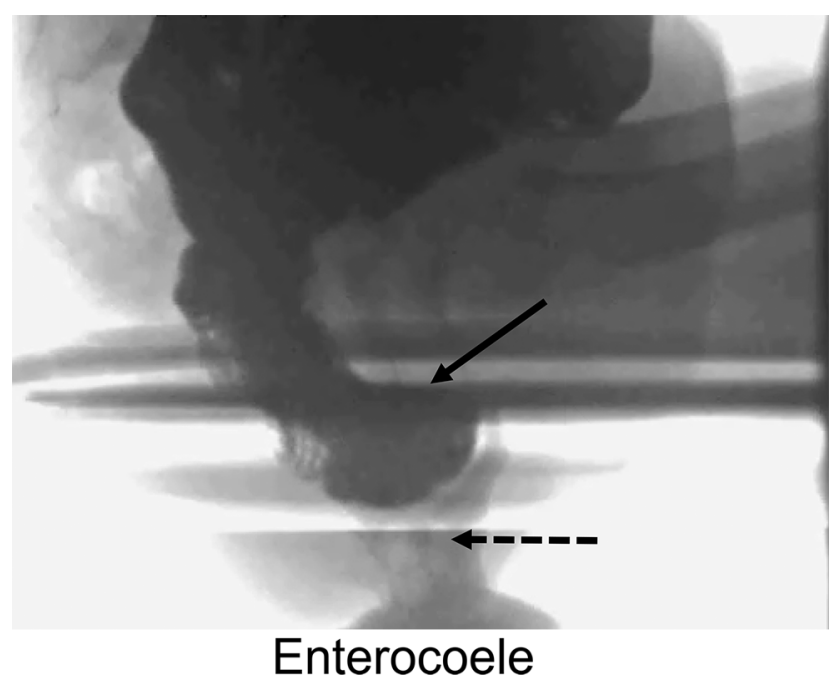

Fig. 4 Barium defaecating proctogram demonstrating an enterocele containing barium opacified small bowel (solid arrow; broken arrow $=$ anal canal).

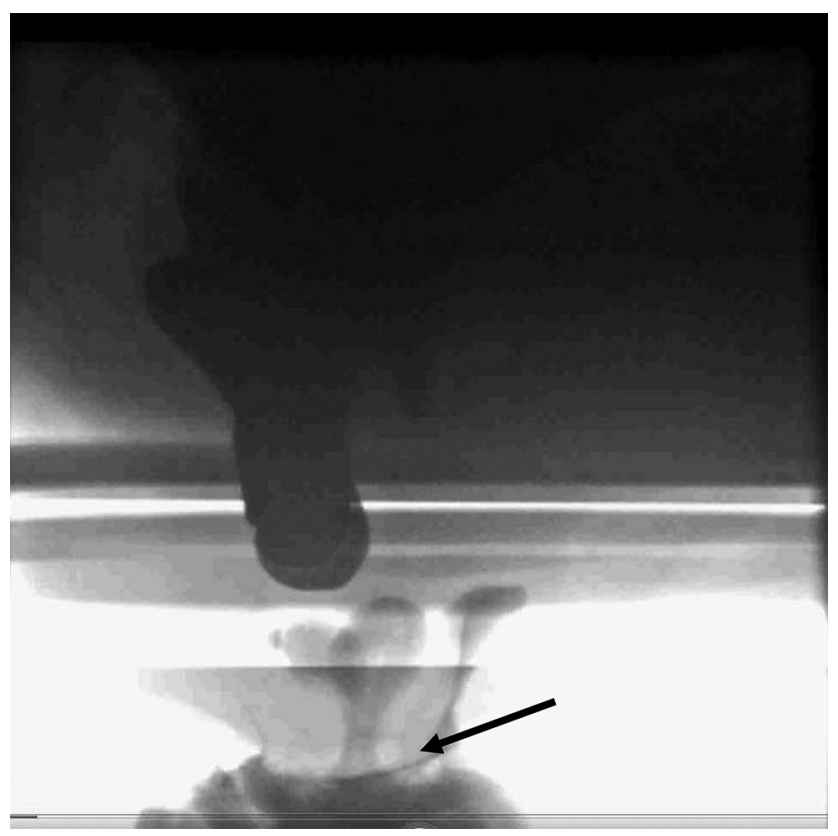

Fig. 5 Barium defaecating proctogram demonstrating a rectal prolapse (arrow).

reported with a low incidence of normal examination (17\%) and anterior rectocele (28\%) being the most common abnormal finding with $3 \%$ of patients having rectal prolapse. $^{7}$

This is the first study to our knowledge to demonstrate that despite a large number of patients having an abnormal BDP finding for various symptoms, few (12\%) go on to have an operation. Obviously, the main indication for operation would be a full thickness rectal prolapse. More recently, however, with the introduction of laparoscopic ventral rectopexy which attempts to restore normal anatomy, operation has been undertaken for lesser degree of prolapse and large rectocoele. ${ }^{89}$ Operation is also undertaken for both urinary and fecal incontinence with variable results. ${ }^{10}$
There was no association between presenting symptoms and the presence of a rectocele in this study. The presence of rectocele is not an uncommon finding on proctography and typically has no physiological or clinical significance. ${ }^{11}$ Therefore, it is important for the clinician to view the abnormalities reported in BDP in the light of symptoms reported by the patient. More than half of the patients (57\%) who underwent BDP were noted to have rectoceles, and 254 had large $(>5 \mathrm{~cm})$ rectoceles. Despite many studies, the true incidence of rectocele remains largely unknown. It has been reported that up to $40 \%$ of parous women have an asymptomatic rectocoele ${ }^{12}$ while Shorvon et al, have identified small rectoceles in 17 of the 21 young, healthy volunteers. ${ }^{13}$ Of the 78 patients who underwent surgery, 17 (22\%) patients underwent multiple potentially life changing procedures, while three ended up with a permanent stoma. This confirms that pelvic floor disorders are often complex and multicompartmental. Patients benefit from a multidisciplinary approach to treatment and BPD is a useful investigation to help identify those who may benefit from a nonsurgical approach.

Defecation proctography was first described by Burhenne in 1964 and has since been accepted as a standard method of assessing patients with PFD. ${ }^{14}$ The limitations of a defecating proctography, however, are well recognized. The artificial setting of how the investigation is performed can often be embarrassing to the patient and can prevent a natural physiological representation. ${ }^{15}$ Interpretation often varies amongst reporting specialists as there is lack of standards of reference, making definitive diagnosis challenging. ${ }^{10}$ Some units will also use MRI as a complementary or alternative method of investigating these patients. ${ }^{16}$ In addition, anorectal manometry is usually performed to assess anal sphincter function as well as rectoanal coordination in patients with PFD.

Pilkington et al performed a comparative study between BDP and MR proctography in patients with pelvic floor disorders. Rather surprisingly, they demonstrated MR proctography under reported pelvic floor abnormalities in patients with poor rectal evacuation. Rectoceles were observed frequently on both tests, however, clinically relevant differences in size up to $2.6 \mathrm{~cm}$ were noted in a proportion of patients. ${ }^{17}$

A limitation of this study is its retrospective nature. A small number of patients who were referred could be lost to follow-up. However, the long interval of follow-up should mean that most patients who underwent surgery would be identified by the regional electronic patient database. This is different from other retrospective studies with shorter follow-up periods and lack of access to an established expansive patient electronic database. A further limitation was the lack of information on how other investigations contributed to decision making in these patients.

\section{Conclusion}

BDP contributes to decision making in patients with PFD. However, results need to be interpreted with caution and 
in conjunction with other tests and clinical examination to maintain a low rate of operation and reduce the risk of adverse outcomes for these patients.

\section{Funding}

None.

\section{Conflict of Interest}

None declared.

\section{References}

1 Bump RC, Norton PA. Epidemiology and natural history of pelvic floor dysfunction. Obstet Gynecol Clin North Am 1998;25(4):723-746

2 Kenton K, Mueller ER. The global burden of female pelvic floor disorders. BJU Int 2006;98(suppl 1) :1-5, discussion 6-7

3 Sung VW, Hampton BS. Epidemiology of pelvic floor dysfunction. Obstet Gynecol Clin North Am 2009;36(3):421-443

4 Altringer WE, Saclarides TJ, Dominguez JM, Brubaker LT, Smith CS. Four-contrast defecography: pelvic "floor-oscopy". Dis Colon Rectum 1995;38(7):695-699

5 Braekken IH, Majida M, Ellström Engh M, Holme IM, Bø K. Pelvic floor function is independently associated with pelvic organ prolapse. BJOG 2009;116(13):1706-1714

6 Data Safe Haven. Available at: https://www.nhsresearchscotland. org.uk/research-in-scotland/data/safe-havens. Accessed October 28, 2019

7 Yang XM, Partanen K, Farin P, Soimakallio S. Defecography. Acta Radiol 1995;36(5):460-468

8 D'Hoore A, Cadoni R, Penninckx F. Long-term outcome of laparoscopic ventral rectopexy for total rectal prolapse. Br J Surg 2004;91(11):1500-1505
9 Ahmad NZ, Stefan S, Adukia V, Naqvi SAH, Khan J. Laparoscopic ventral mesh rectopexy: functional outcomes after surgery. Surg J (N Y) 2018;4(4):e205-e211

10 Laparoscopic ventral mesh rectopexy for internal rectal prolapse. Available at: https://www.nice.org.uk/guidance/ipg618. Accessed November 1, 2019

11 Vrees MD, Weiss EG. The evaluation of constipation. Clin Colon Rectal Surg 2005;18(2):65-75

12 Porter WE, Summitt RL, The Pathophysiology, Diagnosis, and Management of Rectoceles. Global Library of Women's Medicine. Available at: https://www.glowm.com/section_view/heading/ the-pathophysiology-diagnosis-and-management-of-rectoceles/ item $/ 58$

13 Shorvon PJ, McHugh S, Diamant NE, Somers S, Stevenson GW. Defecography in normal volunteers: results and implications. Gut 1989;30(12):1737-1749

14 Burhenne HJ. Intestinal evacuation study: a new roentgenologic technique. Radiol Clin 1964;33:79-84

15 Kim NY, Kim DH, Pickhardt PJ, Carchman EH, Wald A, Robbins JB. Defecography: an overview of technique, interpretation and impact on patient care. Gastroenterol Clin North Am 2018;47(3):553-568

16 Maglinte DD, Hale DS, Sandrasegaran K. Comparison between dynamic cystocolpoproctography and dynamic pelvic floor MRI: pros and cons: which is the "functional" examination for anorectal and pelvic floor dysfunction? Abdom Imaging 2013;38(5):952-973

17 Pilkington SA, Nugent KP, Brenner J, et al. Barium proctography vs magnetic resonance proctography for pelvic floor disorders: a comparative study. Colorectal Dis 2012;14(10):1224-1230 